\title{
BMJ Open Does liberalisation of cannabis policy influence levels of use in adolescents and young adults? A systematic review and meta-analysis
}

\author{
Maria Melchior, ${ }^{\oplus 1}$ Aurélie Nakamura, ${ }^{1}$ Camille Bolze, ${ }^{1}$ Félix Hausfater, ${ }^{1}$ \\ Fabienne El Khoury, ${ }^{2}$ Murielle Mary-Krause, ${ }^{1}$ Marine Azevedo Da Silva ${ }^{3}$
}

To cite: Melchior $\mathrm{M}$, Nakamura A, Bolze C, et al. Does liberalisation of cannabis policy influence levels of use in adolescents and young adults? A systematic review and meta-analysis. BMJ Open 2019;9:e025880. doi:10.1136/ bmjopen-2018-025880

- Prepublication history and additional material for this paper are available online. To view these files, please visit the journal online (http://dx.doi. org/10.1136/bmjopen-2018025880).

Received 9 August 2018 Revised 18 April 2019 Accepted 12 June 2019

Check for updates

(c) Author(s) (or their employer(s)) 2019. Re-use permitted under CC BY-NC. No commercial re-use. See rights and permissions. Published by BMJ.

'Department of Social Epidemiology, INSERM UMRS 1136 IPLESP, Paris, France ${ }^{2}$ Department of Social Epidemiology, INSERM, Paris, France

${ }^{3}$ Department of Epidemiology, Columbia University, New York, USA

Correspondence to

Dr Maria Melchior;

maria.melchior@inserm.fr

\section{ABSTRACT}

Objectives To examine the effect of cannabis policy liberalisation (decriminalisation and legalisation) levels of use in adolescents and young adults.

Design Systematic review and meta-analysis. Inclusion criteria Included studies were conducted among individuals younger than 25 years and quantitatively assessing consequences of cannabis policy change. We excluded articles: (A) exclusively based on participants older than 25 years; (B) only reporting changes in perceptions of cannabis use; (C) not including at least two measures of cannabis use; (D) not including quantitative data; and (E) reviews, letters, opinions and policy papers. PubMed, PsycINF0, Embase and Web of Science were searched through 1 March 2018.

Data extraction and synthesis Two independent readers reviewed the eligibility of titles and abstracts and read eligible articles, and four authors assessed the risk of bias (Quality Assessment Tool for Observational Cohort and Cross-Sectional Studies). Extracted data were meta-analysed. The protocol was registered with PROSPERO.

Results 3438 records were identified via search terms and four via citation lists; 2312 were retained after removal of duplicates, 99 were assessed for eligibility and 41 were included in our systematic review. 13 articles examined cannabis decriminalisation, 20 examined legalisation for medical purposes and 8 examined legalisation for recreational purposes. Findings regarding the consequences of cannabis decriminalisation or legalisation for medical purposes were too heterogeneous to be meta-analysed. Our systematic review and metaanalysis suggest a small increase in cannabis use among adolescents and young adults following legalisation of cannabis for recreational purposes (standardised mean difference of $0.03,95 \% \mathrm{Cl}-0.01$ to -0.07 ). Nevertheless, studies characterised by a very low/low risk of bias showed no evidence of changes in cannabis use following policy modifications.

Conclusions Cannabis policy liberalisation does not appear to result in significant changes in youths' use, with the possible exception of legalisation for recreational purposes that requires monitoring.

Trial registration number CRD42018083950.
Strengths and limitations of this study

- To date, this is the first study to attempt to summarise research on the consequences of various types of changes in cannabis laws and policies (decriminalisation as well as different forms of legalisation) with regard to patterns of use among adolescents and young adults.

- Various data sources in the fields of public health, economics and public policy were searched in a systematic way.

- The duration of follow-up varied across studies, partly because changes in cannabis policy occurred in different periods and places.

- Among studies examining the consequences of the legalisation of cannabis for recreational purposes, only one was characterised by a very low risk of bias and five by a low risk of bias; therefore, the findings will need to be confirmed in future research.

\section{INTRODUCTION}

Cannabis is one of the most frequently used psychoactive substances in North America, Europe, Oceania and North Africa (12 month prevalence of $3.8 \%$ in the world). ${ }^{1}$ Since the 1961 Single Convention on Narcotic Drugs, cannabis is illegal in most countries. However, in the past 20 years, a majority of US states (31 including the District of Columbia) and several countries (eg, Spain, Uruguay and Portugal) have liberalised their cannabis legislation by decriminalising or legalising use for medical or recreational purposes. ${ }^{2}$ Decriminalisation is the reduction of penalties for cannabis use while maintaining penalties for cannabis supply. Legalisation is the permission to use and supply oneself (via home growing or controlled sale). Legalisation for medical use is permission to use and sometimes supply with the involvement of a medical professional (eg, with a doctor's prescription or recommendation). ${ }^{3}$ 
In many settings-especially where cannabis is widely used-public support for legalisation is widespread. ${ }^{45}$ For cannabis users, decriminalised or regulated access to the substance decreases the legal and criminal risks incurred. Potential collective benefits of cannabis policy liberalisation include: (A) reduced law enforcement costs, (B) improvements in the quality of the substance used and (C) in case of commercial legalisation, additional tax revenue. ${ }^{6}$

Still, cannabis is a source of addiction and can have deleterious health consequences in the short and long terms, including impairments in memory and concentration, ${ }^{7}$ risk of injury or respiratory problems. ${ }^{8}$ Moreover, liberalised access to cannabis could also influence the levels of use of other psychoactive substances (eg, tobacco and alcohol).${ }^{910}$ At the same time, there is also evidence that in the USA, the recent increase in opioid use is less marked in states that recently implemented policies liberalising cannabis regulations. ${ }^{11}$

In adults, the liberalisation of cannabis policy has been followed by increases in levels of heavy cannabis use. ${ }^{12-15}$ This may be driven by reductions in the perceived risks, ${ }^{16}$ price decreases, as well as increases in cannabis availability. ${ }^{13}$ However, in adolescents who may be especially vulnerable to the negative consequences of cannabis, ${ }^{7}$ the impact of policy liberalisation is unclear. ${ }^{13}$ As additional US states and European countries are considering liberalising cannabis legislation, there is need to evaluate the potential public health consequences of such policy change.

The objectives of this study were to gain better understanding of the influence of changes in cannabis policy on patterns of use among adolescents and young adults. Youths are a high-risk group in terms of illegal substance use and may be especially sensitive to changes in policy; at the same time they may also be especially vulnerable to the biological, psychological and behavioural consequences of cannabis. Data published before 1 March 2018 on this topic were systematically reviewed and meta-analysed.

\section{METHODS}

\section{Search strategy}

Following Preferred Reporting Items for Systematic Reviews and Meta-Analyses (PRISMA) guidelines, ${ }^{17}$ we conducted a systematic review of studies testing quantitative differences in cannabis use among adolescents and young adults before and after policy change, published prior to 1 March 2018.

Specifically, the following search terms were introduced in PubMed, Web of Science, Embase and PsycINFO: (law* OR decriminalisation OR legalisation) AND (cannabis OR pot OR weed OR marijuana OR grass) AND (young OR youth OR adolescen* OR teen* OR school* OR student). Searches were specified for both MeSH (Medical Subject Headings) terms and text words and were modified to meet the requirements of each database. Only articles in English were identified. All titles and abstracts were independently screened by two of the authors to determine potential eligibility. Full texts of all potentially eligible studies were read by two of the authors (FH and MADS) and discussed with all other authors in case of disagreement. The protocol was registered in PROSPERO and followed the PRISMA framework. ${ }^{17}$ The full search strategy is detailed in online supplementary material figure 1.

\section{Inclusion criteria}

To be included, studies had to be conducted among individuals younger than 25 years and quantitatively assess whether cannabis policy change (defined as decriminalisation or legalisation of cannabis use for medical or recreational purposes) as compared with no change or the situation prior to change was associated with changes in cannabis use. This age limit was selected as it is a meaningful cut-off for the potentially negative biological and social effects of cannabis ${ }^{7}$ as well as a frequently used upper bound to define young people. We excluded articles: (A) exclusively based on participants older than 25 years; (B) only reporting changes in perceptions of cannabis use; (C) not including at least two measures of cannabis use and which did not make it possible to compare changes between before and after policy change; (D) not including quantitative data; and (E) reviews, letters, opinions and policy papers.

\section{Patient and public involvement}

This research was based on analyses of previously published studies and did not involve direct patient involvement.

\section{Risk of bias}

In order to judge the quality of studies that were analysed, risk of bias was assessed using the Quality Assessment Tool for Observational Cohort and Cross-Sectional Studies developed by the National Institute of Health (https://www.nhlbi.nih.gov/health-pro/guidelines/indevelop/cardiovascular-risk-reduction/tools/cohort). Four independent raters evaluated each study (two per article) on up to 11 items including characteristics of the study population, exposure and outcome measurement, time frame adequacy, loss to follow-up (cohort studies; $<20 \%$ being considered as associated with low bias) and adjustment for confounders. Studies defined as presenting a very low risk of bias had no identified flaws. Studies characterised by a low risk of bias provided insufficient information regarding the study time frame or loss to follow-up (where applicable). Studies considered to present a possible risk of bias were characterised by any of the following: (A) insufficient information about the study population recruitment or follow-up (where applicable), (B) insufficient definition of exposure or outcome, (C) a study period of $<1$ year between exposure and outcome or (D) insufficient adjustment for potentially confounding individual or contextual factors. Studies considered to present a probable risk of 
bias were characterised by two or more of the risks identified above. Differences in ratings between coders were discussed in joint meetings.

\section{Data extraction}

A coding sheet was developed to identify: study authors, place of study, type of policy change/study period, participant characteristics (ns), study design, cannabis use measure, statistical methods used/covariates controlled for, key findings and risk of bias.

\section{Meta-analysis}

To meta-analyse the effects of the liberalisation of cannabis policy on levels of use, we calculated standardised mean differences and associated 95\% CIs for each finding using the Practical Meta-Analysis Effect Size Calculator. ${ }^{18}$ Effects sizes from different studies were combined into a weighted mean effect size. Each effect size was weighted by the inverse of its variance and then averaged. ${ }^{19}$ Standard meta-analytical procedures suppose the independence of effects. ${ }^{20}$ However, several primary studies provided multiple correlated effect size estimates for the same underlying outcome (eg, 30-day use and 12-month use). To avoid the loss of information resulting from the selection of only one effect size per study, we used the robust variance estimation method, ${ }^{21}$ which makes it possible to handle statistically dependent effect sizes. A fixed effect meta-analysis was undertaken in the absence of significant heterogeneity; otherwise, a random effects model was used. ${ }^{22}$ To test for homogeneity, we computed the $\mathrm{Q}$ statistic to determine whether each set of effect sizes shared a common population effect size. ${ }^{19}$ To interpret between-study heterogeneity, we used the $\mathrm{I}^{2}$ statistic; an $\mathrm{I}^{2} \leq 50 \%$ is generally considered to indicate low heterogeneity. ${ }^{23}$

To study whether cannabis use in adolescents and young adults varied as a function of: (1) cannabis decriminalisation, (2) legalisation of cannabis use for medical purposes or (3) legalisation of cannabis use for recreational purposes, we conducted three main meta-analyses.

For each type of cannabis policy change, we also performed a priori hypothesised subgroup analyses, according to study design (cohort vs cross-sectional), study year $(<2000$ vs $\geq 2000)$, participants' age $(<18$ years vs $\geq 18$ years) and the measure of cannabis use (30-day use vs 12-month use). Studies included in this review did not present stratified results based on whether participants were $<21$ years versus $\geq 21$ years (the legal age for cannabis use in US states that legalised the substance), making it impossible for us to conduct sensitivity analyses using this age cut-off.

Finally, because the results of a meta-analysis can be biased by studies with non-significant results being less likely to be published, we examined publication bias graphically, using a funnel plot. All analyses were performed using STATA V.14.0 and the robumeta macro. ${ }^{24}$

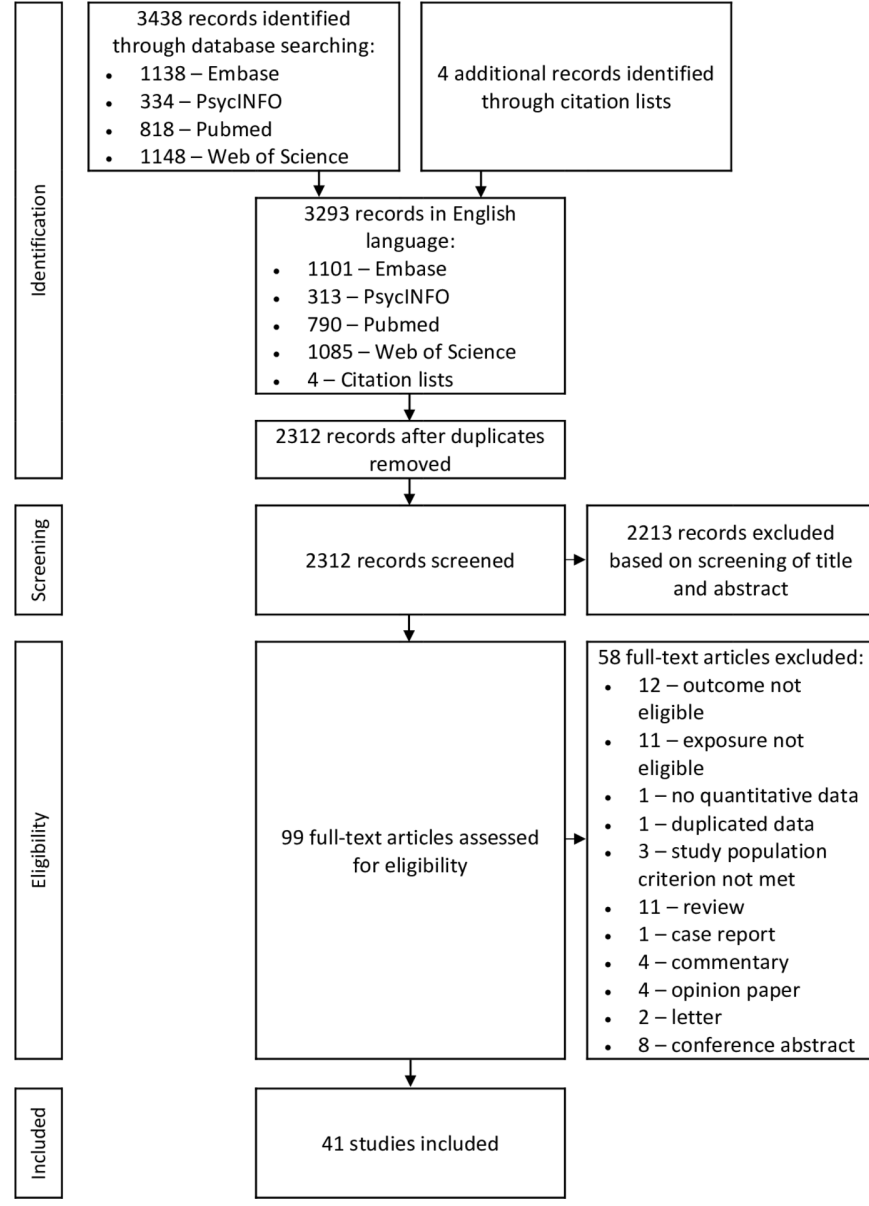

Figure 1 Flow chart showing the screening and selection process of articles selected for the study of the impact of liberalisation of cannabis policy with regard to levels of use in adolescents and young adults.

\section{RESULTS}

The study flow chart (figure 1) shows our search strategy that resulted in the identification of 41 original research reports to be analysed.

The 41 studies analysed were all published in English: 33 were conducted in the USA, ${ }^{1025-56} 3$ in Australia, ${ }^{57-59}$ 2 in the UK, ${ }^{6061} 1$ in the Netherlands, ${ }^{62} 1$ in the Czech Republic $^{63}$ and 1 internationally. ${ }^{54}$ Thirteen studies evaluated the consequences of cannabis decriminalisation, ${ }^{25-28} 3754$ 57-63 20 studies evaluated the consequences of legalisation of use for medical purposes ${ }^{109-3638-4549} 5354$ and 8 studies evaluated the consequences of legalisation of use and possession for recreational purposes. ${ }^{46-4850-5255} 56$ All studies examining the effects of cannabis legalisation (for medical or recreational purposes) were based in the USA.

The reports included were heterogeneous in terms of the populations studied: 21 focused on adolescents (12-17 years),,$^{25} 2831$ 33-35 38 41-44 46-50 53-55 606 on young adults (18-25 years) 374052565759 and 14 included data on both of these groups. ${ }^{142627293032363945515760-62}$

Among studies conducted in the USA, nine were based on the National Study on Drug Use and Health (NSDUH) conducted by the Substance Abuse and Mental Health 
Services Administration (https://nsduhweb.rti.org/ respweb/homepage.cfm), ${ }^{14} 3132363942-45$ seven on the Monitoring The Future study (MTFS; http:/ / monitoringthefuture.org/), ${ }^{10252837384150}$ four on the Youth Behavioral Risk Surveillance survey (YBRS; https://www.cdc. gov/healthyyouth/data/yrbs/index.htm) $)^{33-3549}$ and four on the National Longitudinal Survey of Youths (NLSY79; https://www.nlsinfo.org/content/cohorts/nlsy79, ${ }^{26}{ }^{27}$ and NLSY97 https://www.nlsinfo.org/content/cohorts/ nlsy97. 3340

Among studies conducted in Australia, two were based on the National Drug Strategy Household Survey (http://data.gov.au/dataset/ national-drugs-strategy-household-survey).

Thirty-four studies were based on repeated cross-sectional data, 10252829 31-39 41-45 48-59 61-63 six on longitudinal cohort data 262740464760 and one on analyses of routine administrative data. ${ }^{30}$ Sample sizes in individual studies ranged from $\mathrm{n}=336^{30}$ to $>11703100 .^{35}$

Overall, 16 studies were characterised by a very low risk of bias ${ }^{1014313234-36384144454950575862}$ and 9 by a low risk of bias $262730474851-54$; in our systematic review, only the results of these investigations were analysed. Given the small number of articles in each category, all studies except those with a high level of bias were meta-analysed. In additional analyses, we verified that findings were stable when studies characterised by probable bias were excluded.

\section{Decriminalisation of cannabis use}

As shown in table 1, among the 13 studies examining the consequences of cannabis decriminalisation, three were characterised by a very low risk of bias. ${ }^{575862}$ Two of these-one based in Australia $(n=15468)$ and the second in the Czech Republic $(n=1524)$, and both conducted among adolescents and young adults-found no evidence of statistically significant changes in patterns of cannabis use following policy change. ${ }^{57} 62$ However, one studybased in Australia and conducted exclusively among adolescents aged 12-17 years ( $\mathrm{n}=39$ 0387)-observed a $12 \%$ increase in use following cannabis decriminalisation. ${ }^{58}$ We also identified one study characterised by a low risk of bias ${ }^{26}$ conducted in the USA and focusing on 14-21 year olds $(n=12686)$-which observed no statistically significant effect of cannabis decriminalisation on youths' use.

Meta-analysing all 13 studies, we observed an $\mathrm{I}^{2}$ of $99.5 \%$, indicating high heterogeneity. After excluding studies conducted by Williams and Bretteville-Jensen ${ }^{58}$ and Miech $e t a l^{37}$ (online supplementary figures 1A,B), which appeared to be outliers, the $\mathrm{I}^{2}$ was reduced to $99.1 \%$ but remained too high to conduct a robust meta-analysis. This was unchanged when the analysis was restricted to cohort study data, study year $(<2000$ or $\geq 2000)$, a particular age group (12-17 years or 18-25 years) or recent cannabis use (30 days).

\section{Legalisation of cannabis use for medical purposes}

As shown in table 2, 20 studies examined the consequences of the legalisation of cannabis use for medical purposes in the USA from 1996 onwards. Twelve were characterised by a very low risk of bias. ${ }^{10} 313234-363841444549$ Of those, six were based on NSDUH data, ${ }^{14} 3132364445$ three on the YRBS $^{34} 3549$ and three on the MTFS. ${ }^{10} 3841$ Altogether, six studies (n ranging from 11453 to 11703 100) all conducted among adolescents-one additionally including youths aged $18-20$ years ${ }^{36}$ and one additionally including youths aged $18-25$ years $^{45}$-found no statistically significant effect of the introduction of medical cannabis laws. ${ }^{34-36} 384445$ Three of these studies were based on NSDUH data ${ }^{3644} 45$ and two on the YRBS. ${ }^{34}{ }^{35}$ Importantly, both the NSDUH and the YRBS being repeated cross-sectional surveys, the analytical methods used vary across reports in terms of length of follow-up after policy change (from 1 to 9 years), statistical methods (logistic regression, ${ }^{45}$ difference-in-differences ${ }^{35}$ and fixed-effects models ${ }^{36}$ ), as well as covariates. Still, all studies characterised by a very low risk of bias are adjusted for individual demographic characteristics (age, sex and race) as well as contextual factors (at minima a state identifier and the level of cannabis use prior to policy change). In three studies conducted among adolescents, the legalisation of medical cannabis was followed by a decrease in use. ${ }^{32} 4149$ These three reports were based on different large datasets $\left(\mathrm{NSDUH},{ }^{32} \mathrm{MTFS}^{41}\right.$ and YRBS, ${ }^{49}$ with ns ranging from 11813 to 973089 ). Finally, three studies (ns ranging from 11813 to 973089 ) observed an increase in levels of cannabis use among adolescents (under 18 years) living in a state that passed medical cannabis laws ${ }^{10} 1431$ and one of these observed a similar effect among young adults (ages $18-25$ years). ${ }^{14}$

Two studies were characterised by a low risk of bias. ${ }^{30} 53$ One, based on routine data (Arrestee Drug Abuse Monitoring system, $n=336$ ), showed no statistically significant differences in the prevalence of cannabis use (as ascertained by urine tests) among persons seen in hospital emergency departments before and after medical cannabis laws. ${ }^{30}$ The second study reported that among cannabis users recruited via social media $(n=2630)$, the level of cannabis vaping and eating varied with the time since legalisation of medical cannabis-the longer the time since legalisation, the higher the likelihood of use. ${ }^{53}$

Importantly, these data indicate that the provisions of laws enabling access to cannabis for medical purposes, such as the amount of cannabis that individuals are allowed to possess and use, the existence of patient registries, ${ }^{49}$ the proportion of dispensaries per inhabitant, the authorisation of home cultivation or concomitant laws making it legal to use cannabis for recreational purposes ${ }^{53}$ are influential and should be systematically reported by researchers examining the effects of cannabis policies.

Meta-analysing all 20 studies, we observed an $\mathrm{I}^{2}$ of $100 \%$, indicating high heterogeneity. After excluding the studies conducted by Wen $e t a l^{36}$ and Harper $e t a l,{ }^{32}$ which 


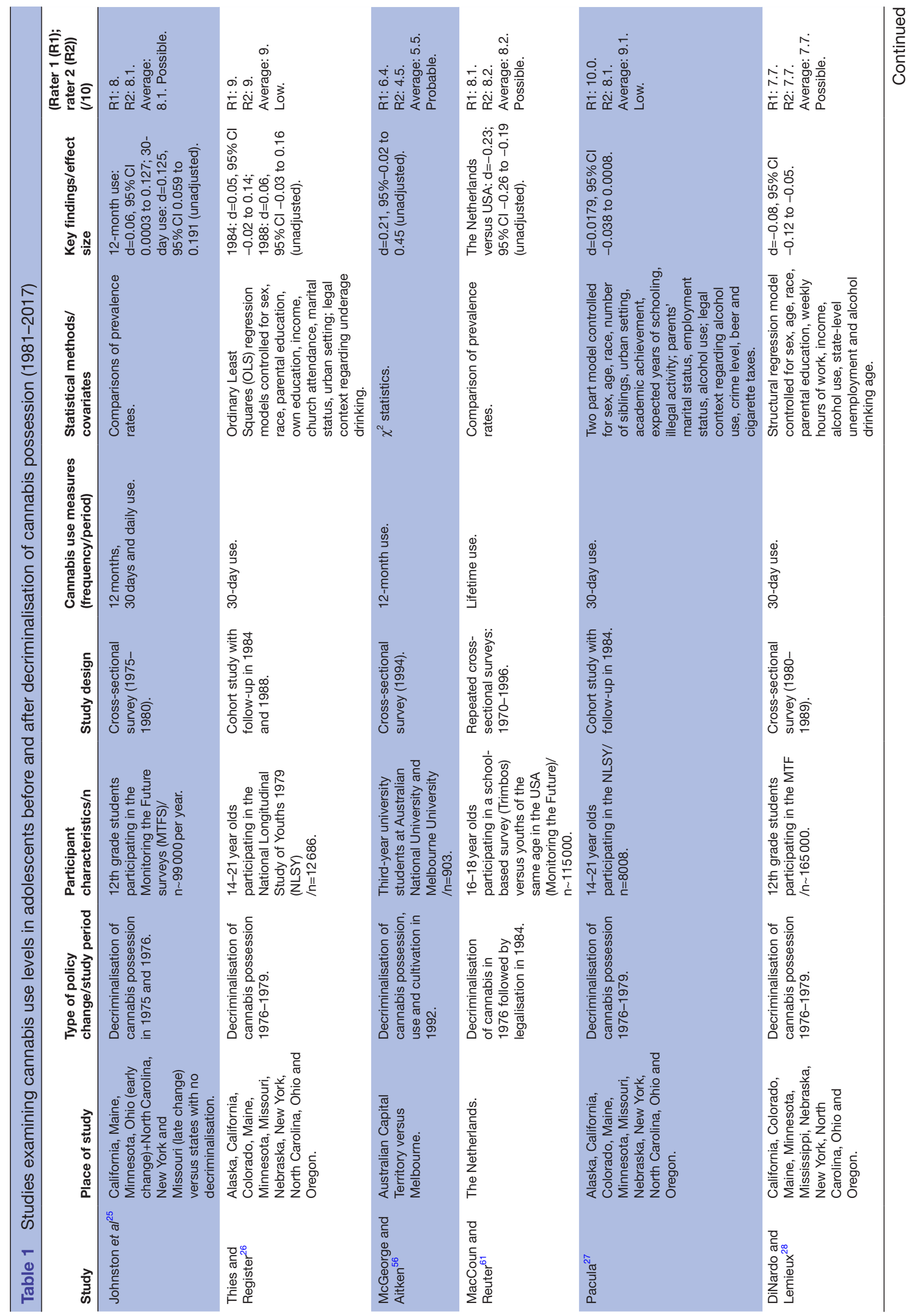




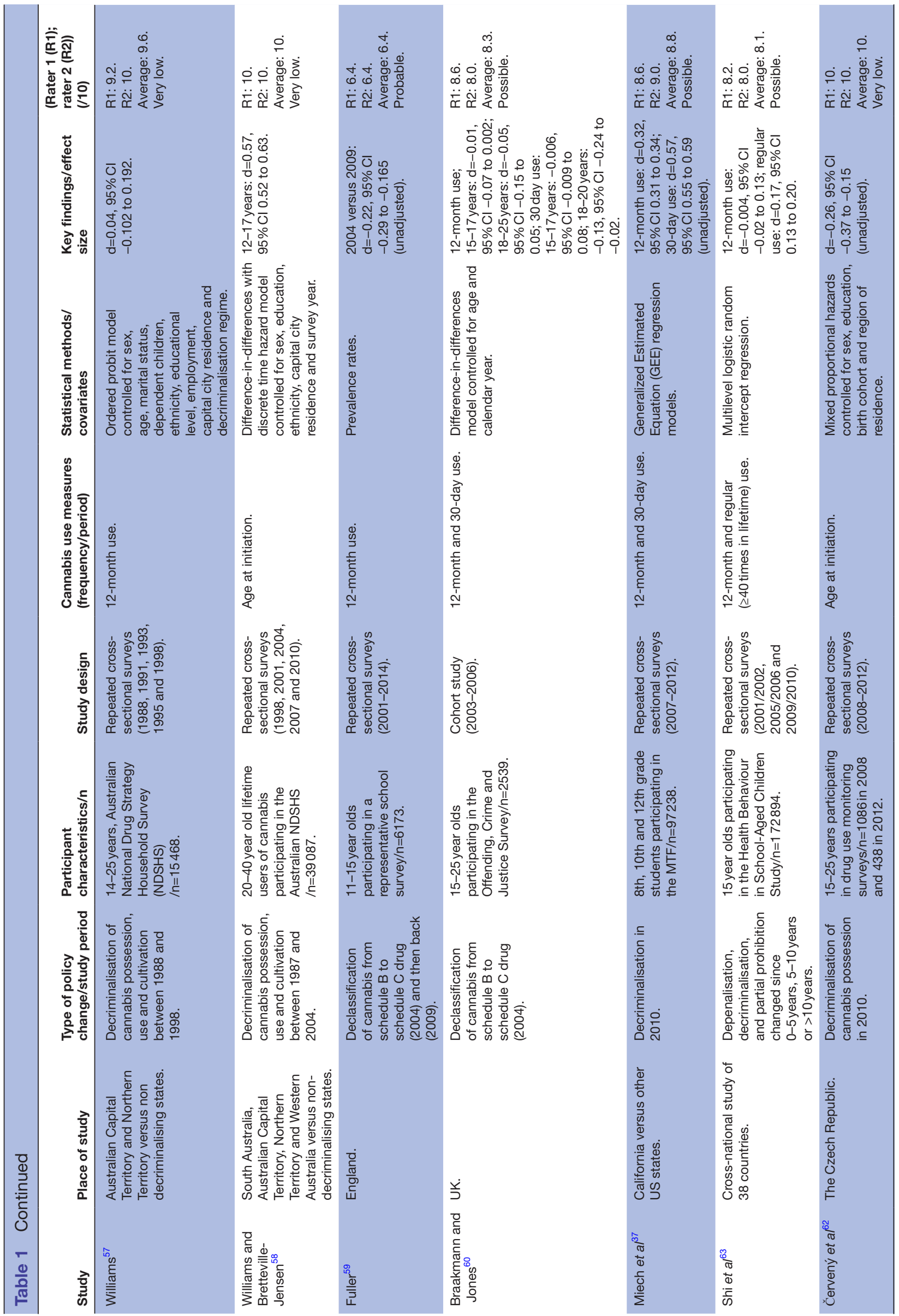




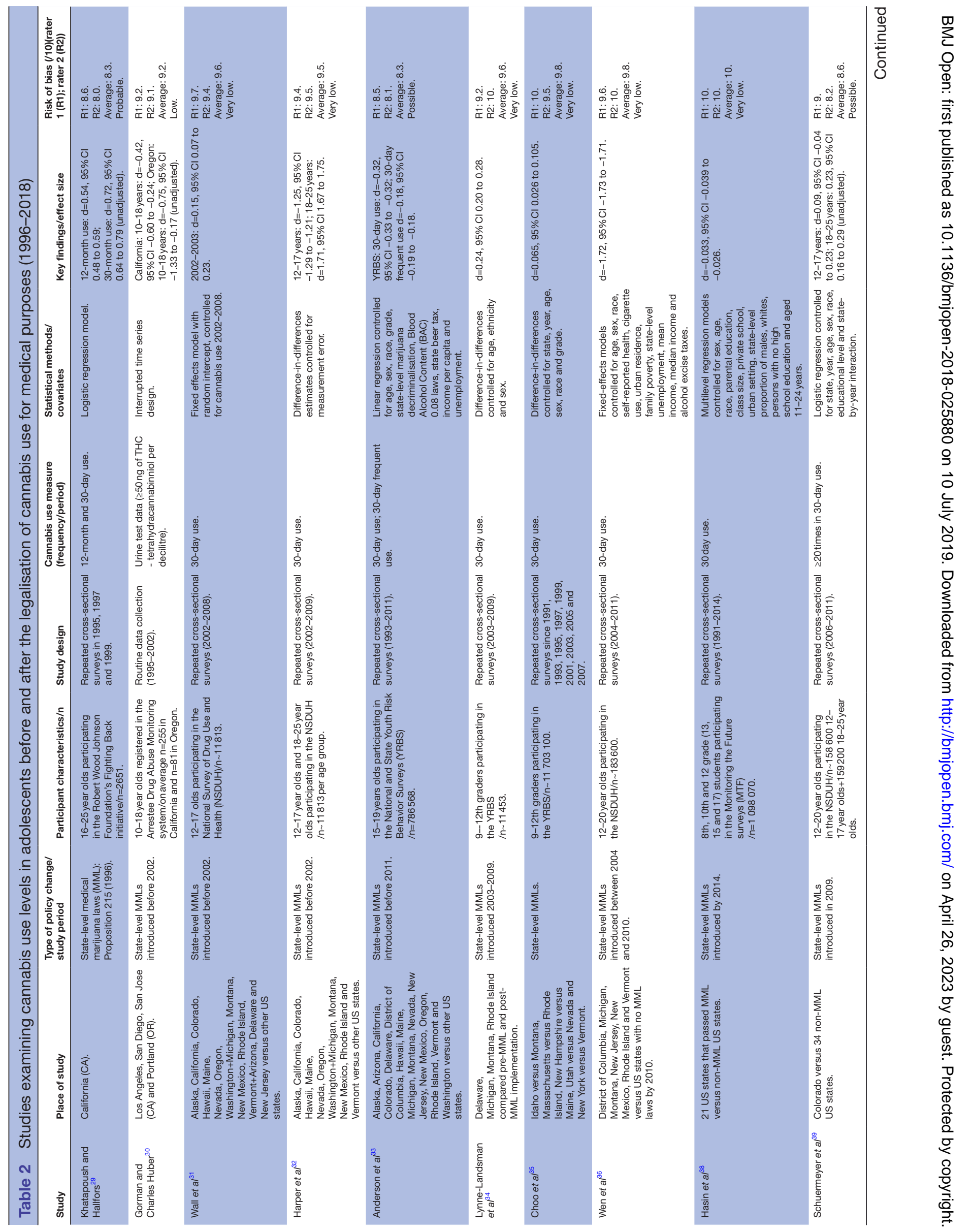




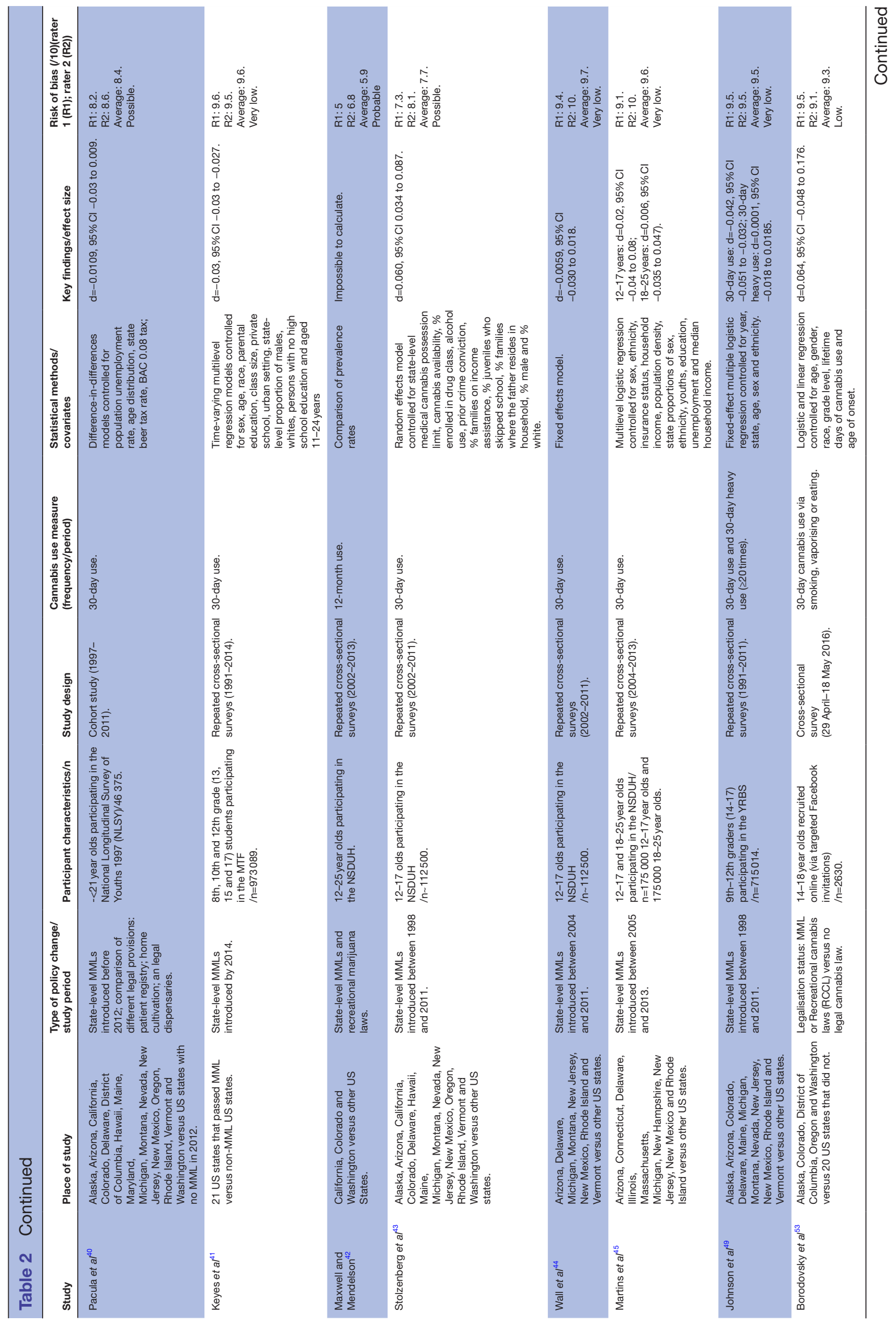

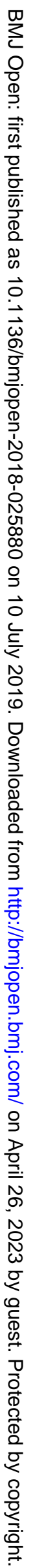




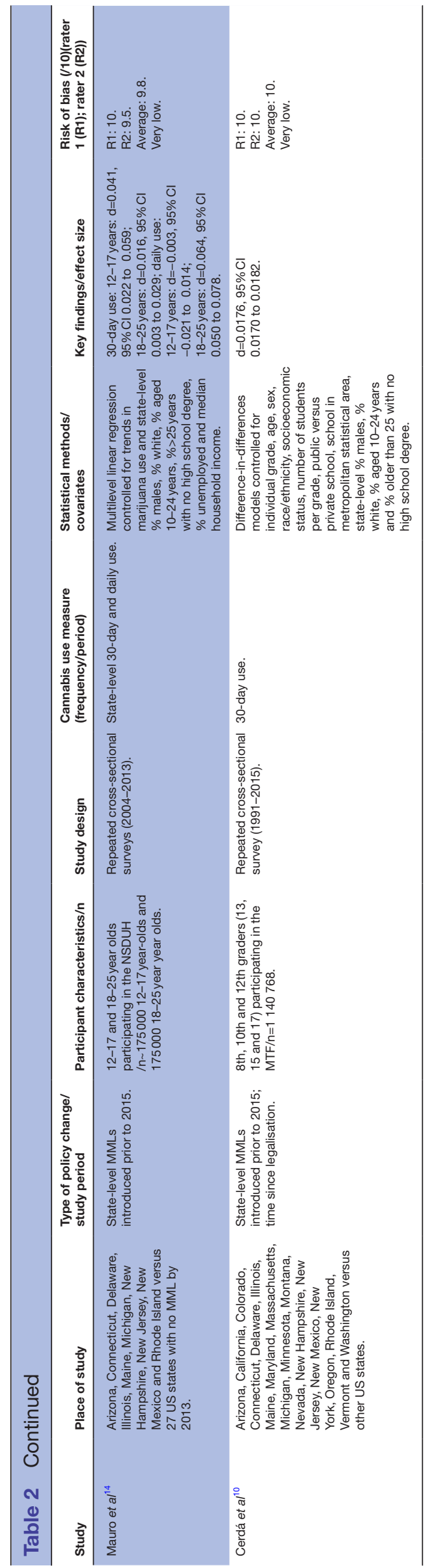

appeared to be outliers (online supplementary figures $2 A, B)$, the $\mathrm{I}^{2}$ was reduced to $98.6 \%$ but remained too high to conduct a robust meta-analysis. This was unchanged when the analysis was restricted to cohort studies, study year $(<2000$ or $\geq 2000)$, a particular age group $(12-17$ or 18-25 years) or recent cannabis use (30 days).

\section{Legalisation of cannabis for recreational purposes}

As shown in table 3, we identified eight studies examining the impact of recreational cannabis laws, which make it legal to use and possess small amounts of cannabis, on youths. They were all conducted in the USA, where several states have introduced this form of cannabis legalisation since 2012. Four studies were based in Washington state, ${ }^{46-4852}$ two in Colorado, ${ }^{5455}$ one in Washington state and Colorado ${ }^{50}$ and one in Oregon. ${ }^{51}$ Only one studybased on the MTFS - was characterised by a very low risk of bias. ${ }^{50}$ This investigation ( $\left.\mathrm{n}=253902\right)$ reported a statistically significant increase in cannabis use among adolescents living in Washington state $3.2 \%$ increase among 8th graders and $5.0 \%$ increase among 10th graders) but not among those living in Colorado.

We also identified two studies characterised by a low risk of bias. One $(n=13335)$ reported a $2.0 \%-3.5 \%$ increase in the frequency of cannabis use among college students living in Washington state ${ }^{52}$ and the other an increase of. $02 \%$ among middle and high school students living in Colorado $(\mathrm{n}=24171) .^{54}$

Meta-analysing all eight studies, we observed an $\mathrm{I}^{2}$ of $89.8 \%$, indicating high heterogeneity (online supplementary figures $3 \mathrm{~A}, \mathrm{~B})$. After excluding the study conducted by Cerdá et $a l l^{50}$ which appeared to be an outlier, the $\mathrm{I}^{2}$ was reduced to $45.0 \%$. This analysis yielded an average standardised mean difference of 0.03 (95\% CI -0.01 to 0.07 ), suggesting a possible small increase in the use of cannabis following the legalisation of recreational cannabis.

\section{DISCUSSION \\ Main findings}

Our systematic review of studies examining the impact of the liberalisation of cannabis legislation on patterns of use among adolescents and young people, identified 41 reports published prior to March 2018, 16 characterised by a very low risk of bias and 9 by a low risk of bias. With the exception of one study, high-quality reports examining the impact of cannabis decriminalisation $(n=4)$ show no statistically significant change in youths' patterns of use. Similarly, the legalisation of cannabis use for medical purposes, extensively evaluated in the USA, does not appear to have an effect: six studies suggest no change in cannabis use among youths, three studies observe a decrease and four studies report an increase. However, the legalisation of cannabis for recreational purposes, examined in six studies with a very low or low risk of bias, may be associated with a small increase in levels of use among youths. 


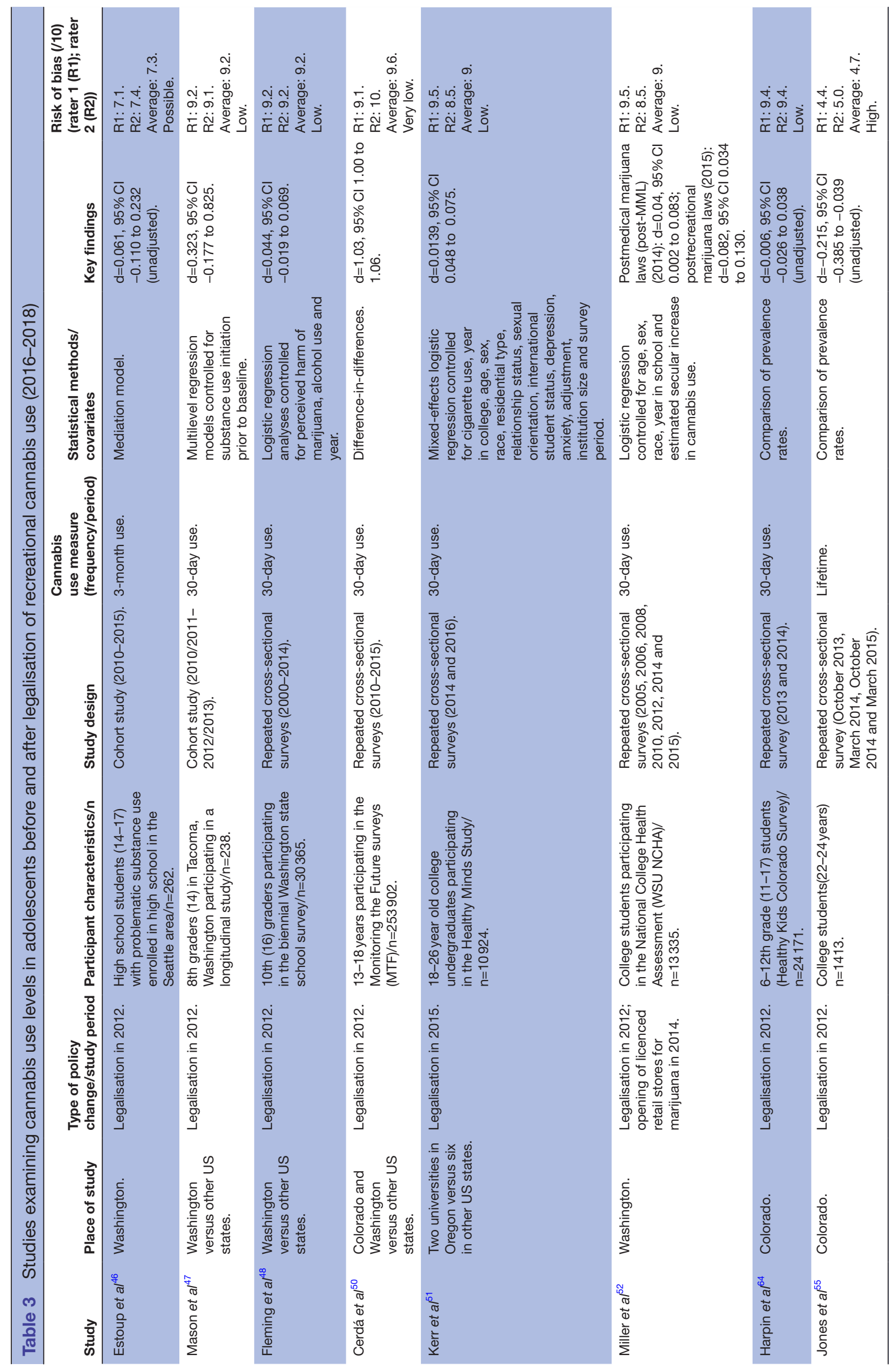


Overall, policies regarding cannabis use and possession seem to have little effect on actual patterns of use among young people, with the possible exception of the legalisation of recreational use. To date, evidence regarding the impact of the legalisation of recreational cannabis comes from the USA, where prevalence levels of substance use are high and laws liberalising cannabis use tend to be market oriented. Additional data from other settings (eg, Uruguay and Canada) will help gain a better understanding of relations between cannabis policy and patterns of use in the population.

\section{Limitations and strengths}

Our systematic review and meta-analysis has limitations that need to be acknowledged. First, the specific provisions of laws and policies regulating cannabis and that can influence actual access to the substance ${ }^{2}$ vary across settings. For example, decriminalisation can imply different limits on the amount of cannabis that leads to a fine; for example, the possession of $15 \mathrm{~g}$ of herb or $5 \mathrm{~g}$ of resin in the Czech Republic is fined approximately 550 euros $^{62}$; in the Australian Capital Territory (Canberra region), the possession of up to $25 \mathrm{~g}$ is fined approximately 100 euros, while in Western Australia (Perth region), the possession of less than $10 \mathrm{~g}$ is tolerated but higher quantities can result in a conviction. ${ }^{64}$ Similarly, laws allowing the use and possession of cannabis for medical purposes, currently in place in approximately 20 countries (eg, Australia, Belgium, Spain, Canada and some US states) take different forms. For instance, only the Netherlands and some US states make it possible for individuals to purchase or grow cannabis that can be smoked; in other settings, individuals can purchase specific medicines derived from cannabinoids (eg, the UK). The legal age at which individuals are authorised to possess cannabis (18 or 21 years) varies across settings, with possibly differential effects on levels of use among young adults. Finally, the price of cannabis, which influences levels of use among young people, ${ }^{5765}$ varies from place to place and over time. Clearly, differences in specific policy provisions, which have an impact on cannabis availability, make it difficult to compare different settings. Nevertheless, at the time of its implementation or even before if there is wide media coverage, policy change in and of itself can influence the perceptions of cannabis, which in turn shape levels of use, ${ }^{41}$ justifying the conduct of this systematic review. Second, the duration of follow-up varies across studies, in part because changes in cannabis policy occurred in different periods and places. This is especially a concern for reports evaluating the impact of recreational cannabis laws: policy changes introduced decades ago (eg, the Netherlands) were not fully evaluated, while follow-up is limited for more recent policy modifications (eg, the USA and Uruguay). It is unclear whether the introduction of policies that liberalise cannabis use and possession is most likely to influence patterns of use in the short term or in the long term; in the present report, we considered that a follow-up period of at least 1year following actual policy implementation was necessary to test a possible effect. Third, among studies examining the consequences of the legalisation of cannabis for recreational purposes, we only identified one study characterised by a very low risk of bias and five studies by a low risk of bias, and the findings we report will need to be confirmed. Our attempt to meta-analyse the results of different studies included in this review proved inconclusive, with the exception of legalisation of cannabis for recreational purposes: this calls for additional, methodologically robust, studies in this area. Fourth, although changes in cannabis policies have occurred in various settings, most studies included in this report were conducted in the USA, where most research in this area has been conducted. It is difficult to assess the extent to which the findings observed in the USA will generalise to other countries, and it will be important to update knowledge in this area once data from other places (eg, Uruguay and Canada) become available.

Despite these limitations, our study has several strengths: (A) the evaluation of studies published in different disciplines (public health, epidemiology, economics and social policy) through multiple databases; (B) the combination of data from different settings (USA, Australia and Europe); (C) special attention to the risk of bias, examined using a framework especially developed for observational studies. Moreover, our systematic review takes into consideration different forms of liberalisation of cannabis policies (decriminalisation, legalisation for medical purposes and for recreational purposes), attempting to tackle this complex issue in a thorough way.

\section{Methodological issues}

The studies included in this systematic review relied on several different datasets and applied quite varied methods (logistic regression, ${ }^{45}$ difference-in-differences ${ }^{35}$ and fixed-effects models ${ }^{36}$ ) to isolate the effects of policy change on patterns of cannabis use independently of individual and contextual characteristics; such triangulation of different methods is considered especially reliable when, as in this case, it yields consistent results. ${ }^{66}$ Importantly, because cannabis policy changes most often occur in settings where public support and levels of use are high, it is essential to take into account levels of cannabis use prior to policy change, as was the case in all reports we considered to present a very low or low risk of bias. Finally, it is important to note that we evaluated relative changes in cannabis use postpolicy versus prepolicy change. Levels of cannabis use vary widely across settings and in some places may have been so high prior to policy change that additional increases are unlikely (this may be the case of Colorado where over $25 \%$ of 12 th graders use cannabis on a monthly basis). ${ }^{50}$

Most studies included in our systematic review were cross-sectional, because reports based on longitudinal data are less numerous and were not always of sufficiently high quality. While repeated cross-sectional studies are well suited to examine long-term changes in patterns of cannabis use in relation to changes in the legal context, additional evidence from longitudinal data following young people would make it possible to take into account 
individual characteristics and further strengthen the inference that can be drawn regarding the impact of cannabis policy change.

\section{Implications}

Summarising the available evidence, we found that, contrary to what has been observed in adults, ${ }^{365767}$ cannabis decriminalisation and legalisation for medical purposes are probably not related to significant changes in patterns of use among adolescents and young people. This was also recently reported by a systematic review and meta-analysis that focused on medical cannabis laws and patterns of use in the preceding 30 days among adolescents. ${ }^{68}$ However, the legalisation of cannabis use for recreational purposes may lead to higher levels of use in this age group and a younger age at initiation. Several hypotheses have been proposed to explain this multifactorial phenomenon: (A) changes in the reporting of cannabis use; (B) a decrease in perceived harmfulness ${ }^{41}$; (C) an increase in cannabis availability and access; and (D) a decrease in price (in legal outlets or on the black market) ${ }^{69}$ While the liberalisation of cannabis policy can have both collective and individual benefits (eg, decrease in costs of law enforcement, increase in quality control and reduction in individuals' difficulties with the legal system), these data suggest the possibility of small negative public health implications. Adolescents and young adults are especially vulnerable to the consequences of cannabis use, in terms of both biological and social development $^{7071}$; therefore, policies that involve the legalisation of recreational use of cannabis need to be accompanied by prevention efforts targeted towards young people. The most effective prevention programmes aim to improve school climate and strengthen youths' psychosocial skills such as self-esteem and conflict resolution. ${ }^{72} 73$

\section{CONCLUSION}

In recent decades, cannabis policies have been liberalised in different ways (decriminalisation, legalisation of use for medical or recreational purposes) and in various settings. Our systematic review and meta-analysis of 41 research articles published across disciplines (epidemiology, economics and social policy) and using a variety of datasets and statistical methods shows that cannabis decriminalisation or legalisation of use for medical purposes do not result in higher levels of use among youths. Legalisation of use for recreational purposes appears to possibly result in a small increase. It will be important to reassess whether this tendency persists over time, varies across subgroups of youths (male vs female, urban vs rural, socioeconomically disadvantaged vs favoured) and is comparable across settings, particularly as additional countries introduce changes in cannabis policy (eg, Canada). Repeated cross-sectional as well as longitudinal studies will be necessary to thoroughly evaluate adolescents' levels of cannabis use following changes in policy.
Contributors MM had the original idea for the study and proposed the study design. FH and MADS conducted the literature search, screened and selected the studies initially identified. MM, CB, MADS and MM-K read and evaluated the quality of the studies included. AN and FEK conducted the meta-analysis. MM wrote the initial manuscript and serves as guarantor. All authors contributed to interpreting the study findings and to the final manuscript.

Funding The authors have not declared a specific grant for this research from any funding agency in the public, commercial or not-for-profit sectors.

Competing interests None declared.

Patient consent for publication Not required.

Provenance and peer review Not commissioned; externally peer reviewed.

Data sharing statement № additional data are available.

Open access This is an open access article distributed in accordance with the Creative Commons Attribution Non Commercial (CC BY-NC 4.0) license, which permits others to distribute, remix, adapt, build upon this work non-commercially, and license their derivative works on different terms, provided the original work is properly cited, appropriate credit is given, any changes made indicated, and the use is non-commercial. See: http://creativecommons.org/licenses/by-nc/4.0/.

\section{REFERENCES}

1. United Nations Office for Drugs and Crime. The world drug report 2016. New York: United Nations, 2016.

2. Klieger SB, Gutman A, Allen L, et al. Mapping medical marijuana: state laws regulating patients, product safety, supply chains and dispensaries, 2017. Addiction 2017;112:2206-16.

3. European Monitoring Center for Drugs and Drug Addiction. Decriminalisation in Europe? Recent developments in legal approaches to drug use. European Legal Database on Drugs (ELDD) comparative study. European Legal Database on Drugs. Lisbon: EMCDDA, 2001

4. Mendiburo-Seguel A, Vargas S, Oyanedel JC, et al. Attitudes towards drug policies in Latin America: results from a Latin-American Survey. Int J Drug Policy 2017;41:8-13.

5. Cohn AM, Johnson AL, Rose SW, et al. Support for marijuana legalization and predictors of intentions to use marijuana more often in response to legalization among U.S. young adults. Subst Use Misuse 2017;52:203-13.

6. McGinty EE, Niederdeppe J, Heley K, et al. Public perceptions of arguments supporting and opposing recreational marijuana legalization. Prev Med 2017;99:80-6.

7. Volkow ND, Swanson JM, Evins AE, et al. Effects of Cannabis use on human behavior, including cognition, motivation, and psychosis: a review. JAMA Psychiatry 2016;73:292-7.

8. Hall W, Degenhardt L. The adverse health effects of chronic cannabis use. Drug Test Anal 2014;6:39-45.

9. Azofeifa A, Mattson ME, Grant A. Monitoring marijuana use in the United States: challenges in an evolving environment. JAMA 2016;316:1765-6.

10. Cerdá M, Sarvet AL, Wall M, et al. Medical marijuana laws and adolescent use of marijuana and other substances: Alcohol, cigarettes, prescription drugs, and other illicit drugs. Drug Alcohol Depend 2018;183:62-8.

11. Powell $D$, Pacula RL, Jacobson M. Do medical marijuana laws reduce addictions and deaths related to pain killers? $J$ Health Econ 2018;58:29-42.

12. Chu YW. The effects of medical marijuana laws on illegal marijuana use. J Health Econ 2014;38:43-61.

13. Hall W, Lynskey M. Evaluating the public health impacts of legalizing recreational cannabis use in the United States. Addiction 2016;111:1764-73.

14. Mauro CM, Newswanger P, Santaella-Tenorio J, et al. Impact of medical marijuana laws on state-level marijuana use by age and gender, 2004-2013. Prev Sci 2019;20:205-14.

15. Carliner H, Brown QL, Sarvet AL, et al. Cannabis use, attitudes, and legal status in the U.S: a review. Prev Med 2017;104:13-23.

16. Azofeifa A, Mattson ME, Schauer G, et al. National estimates of marijuana use and related indicators - National Survey on drug use and Health, United States, 2002-2014. MMWR Surveill Summ 2016;65:1-28.

17. Moher D, Liberati A, Tetzlaff J, et al. Preferred reporting items for systematic reviews and meta-analyses: the PRISMA statement. PLOS Med 2009;6:e1000097.

18. Wilson DB. Practical meta-analysis effect size calculator. $2018 \mathrm{http}: / /$ www.campbellcollaboration.org/escalc/html/EffectSizeCalculatorSMD9.php (Accessed 30 Apr 2018). 
19. Lipsey M, Wilson D. Practical meta-analysis. Thousand Oaks, CA: Sage publications, 2001

20. Gleser LJ, Olkin I. Stochastically dependent effect sizes: randomeffects models. In: Cooper LVHaJCV H, ed. The handbook of research synthesis and meta-analysis. New York, NY: Russell Sage Foundation, 2009:357-76.

21. Hedges LV, Tipton E, Johnson MC. Robust variance estimation in meta-regression with dependent effect size estimates. Res Synth Methods 2010;1:39-65.

22. Borenstein M, Hedges LV, Higgins JP, et al. A basic introduction to fixed-effect and random-effects models for meta-analysis. Res Synth Methods 2010;1:97-111.

23. Higgins JP, Thompson SG, Deeks JJ, et al. Measuring inconsistency in meta-analyses. BMJ 2003;327:557-60.

24. STATA. College Station, TX: StataCorp LP. 2015

25. Johnston LD, O'Malley P, Bachman J. Marijuana decriminalization: the impact on youth. 1975-1980. Ann Arbor, MI: Institute of Social Research 1981.

26. Thies CF, Register CA. Decriminalization of marijuana and the demand for alcohol, marijuana and cocaine. Soc Sci J 1993:30:385-99.

27. Pacula RL. Does increasing the beer tax reduce marijuana consumption? J Health Econ 1998;17:557-85.

28. DiNardo J, Lemieux T. Alcohol, marijuana, and American youth: the unintended consequences of government regulation. $J$ Health Econ 2001;20:991-1010.

29. Khatapoush S, Hallfors D. "Sending the wrong message": did medical marijuana legalization in california change attitudes about and use of marijuana? J Drug Issues 2004;34:751-70.

30. Gorman DM, Charles Huber J. Do medical cannabis laws encourage cannabis use? Int J Drug Policy 2007:18:160-7.

31. Wall MM, Poh E, Cerdá M, et al. Adolescent marijuana use from 2002 to 2008: higher in states with medical marijuana laws, cause still unclear. Ann Epidemiol 2011;21:714-6.

32. Harper S, Strumpf EC, Kaufman JS. Do medical marijuana laws increase marijuana use? Replication study and extension. Ann Epidemiol 2012;22:207-12.

33. Anderson DM, Hansen B, Rees DI. Medical marijuana laws and teen marijuana use. SSRN Electronic Journal 2012.

34. Lynne-Landsman SD, Livingston MD, Wagenaar AC. Effects of state medical marijuana laws on adolescent marijuana use. Am J Public Health 2013;103:1500-6.

35. Choo EK, Benz M, Zaller N, et al. The impact of state medical marijuana legislation on adolescent marijuana use. $J$ Adolesc Health 2014:55:160-6.

36. Wen $\mathrm{H}$, Hockenberry JM, Cummings JR. The effect of medical marijuana laws on marijuana, alcohol and hard drug use. In: Narional Bureau of Economic Research. Cambridge, MA, 2014

37. Miech RA, Johnston L, O'Malley PM, et al. Trends in use of marijuana and attitudes toward marijuana among youth before and after decriminalization: the case of California 2007-2013. Int J Drug Policy 2015;26:336-44.

38. Hasin DS, Wall M, Keyes KM, et al. Medical marijuana laws and adolescent marijuana use in the USA from 1991 to 2014: results from annual, repeated cross-sectional surveys. Lancet Psychiatry 2015;2:601-8.

39. Schuermeyer J, Salomonsen-Sautel S, Price RK, et al. Temporal trends in marijuana attitudes, availability and use in Colorado compared to non-medical marijuana states: 2003-11. Drug Alcohol Depend 2014;140:145-55

40. Pacula RL, Powell D, Heaton P, et al. Assessing the effects of medical marijuana laws on marijuana use: the devil is in the details. $J$ Policy Anal Manage 2015;34:7-31.

41. Keyes KM, Wall M, Cerdá M, et al. How does state marijuana policy affect US youth? Medical marijuana laws, marijuana use and perceived harmfulness: 1991-2014. Addiction 2016;111:2187-95.

42. Maxwell JC, Mendelson B. What do we know now about the impact of the laws related to marijuana? J Addict Med 2016;10:3-12.

43. Stolzenberg L, D'Alessio SJ, Dariano D. The effect of medical cannabis laws on juvenile cannabis use. Int J Drug Policy 2016;27:82-8.

44. Wall MM, Mauro C, Hasin DS, et al. Prevalence of marijuana use does not differentially increase among youth after states pass medical marijuana laws: commentary on and reanalysis of US National Survey on Drug Use in Households data 2002-2011. Int J Drug Policy 2016;29:9-13.

45. Martins SS, Mauro CM, Santaella-Tenorio J, et al. State-level medical marijuana laws, marijuana use and perceived availability of marijuana among the general U.S. population. Drug Alcohol Depend 2016;169:26-32.
46. Estoup AC, Moise-Campbell C, Varma M, et al. The impact of marijuana legalization on adolescent use, consequences, and perceived risk. Subst Use Misuse 2016;51:1881-7.

47. Mason WA, Fleming CB, Ringle JL, et al. Prevalence of marijuana and other substance use before and after Washington State's change from legal medical marijuana to legal medical and nonmedical marijuana: Cohort comparisons in a sample of adolescents. Subst Abus 2016;37:330-5.

48. Fleming CB, Guttmannova K, Cambron C, et al. Examination of the divergence in trends for adolescent marijuana use and marijuanaspecific risk factors in Washington State. $J$ Adolesc Health 2016;59:269-75.

49. Johnson J, Hodgkin D, Harris SK. The design of medical marijuana laws and adolescent use and heavy use of marijuana: Analysis of 45 states from 1991 to 2011. Drug Alcohol Depend 2017:170:1-8.

50. Cerdá M, Wall M, Feng T, et al. Association of state recreational marijuana laws with adolescent marijuana use. JAMA Pediatr 2017:171:142-9.

51. Kerr DCR, Bae H, Phibbs S, et al. Changes in undergraduates' marijuana, heavy alcohol and cigarette use following legalization of recreational marijuana use in Oregon. Addiction 2017;112:1992-2001.

52. Miller AM, Rosenman R, Cowan BW. Recreational marijuana legalization and college student use: Early evidence. SSM Popul Health 2017;3:649-57.

53. Borodovsky JT, Lee DC, Crosier BS, et al. U.S. cannabis legalization and use of vaping and edible products among youth. Drug Alcohol Depend 2017;177:299-306.

54. Harpin SB, Brooks-Russell A, Ma M, et al. Adolescent marijuana use and perceived ease of access before and after recreational marijuana implementation in Colorado. Subst Use Misuse 2018;53:451-6.

55. Jones J, Nicole Jones K, Peil J. The impact of the legalization of recreational marijuana on college students. Addict Behav 2018;77:255-9.

56. McGeorge J, Aitken CK. Effects of cannabis decriminalization in the Australian Capital Territory on University Students' patterns of use. $J$ Drug Issues 1997;27:785-94.

57. Williams $J$. The effects of price and policy on marijuana use: what can be learned from the Australian experience? Health Econ 2004:13:123-37.

58. Williams J, Bretteville-Jensen AL. Does liberalizing cannabis laws increase cannabis use? J Health Econ 2014;36:20-32.

59. Fuller E. Smoking, drinking and drug use among young people in England in 2014. London: National Center for Social Research, 2014

60. Braakmann $\mathrm{N}$, Jones S. Cannabis depenalisation, drug consumption and crime - evidence from the 2004 cannabis declassification in the UK. Soc Sci Med 2014;115:29-37.

61. MacCoun R, Reuter P. Interpreting Dutch cannabis policy: reasoning by analogy in the legalization debate. Science 1997;278:47-52.

62. Červený J, Chomynová P, Mravčík V, et al. Cannabis decriminalization and the age of onset of cannabis use. International Journal of Drug Policy 2017;43:122-9.

63. Shi Y, Lenzi M, An R. Cannabis liberalization and adolescent cannabis use: a cross-national study in 38 countries. PLoS One 2015;10:e0143562.

64. McDonald D, Moore R, Norberry J, et al; Legislative options for cannabis in Australia. Canberra: Australian Government Publishing Service, 1994.

65. van Ours JC, Williams J. Cannabis prices and dynamics of cannabis use. J Health Econ 2007;26:578-96.

66. Lawlor DA, Tilling K, Davey Smith G. Triangulation in aetiological epidemiology. Int J Epidemiol 2016;45:1866-86.

67. Hasin DS, Sarvet AL, Cerdá M, et al. US Adult illicit cannabis use, cannabis use disorder, and medical marijuana laws: 1991-1992 to 2012-2013. JAMA Psychiatry 2017;74:579-88.

68. Sarvet AL, Wall MM, Fink DS, et al. Medical marijuana laws and adolescent marijuana use in the United States: a systematic review and meta-analysis. Addiction 2018;113:1003-16.

69. MacCoun RJ. What can we learn from the Dutch cannabis coffeeshop system? Addiction 2011;106:1899-910.

70. Trezza V, Cuomo V, Vanderschuren LJ. Cannabis and the developing brain: insights from behavior. Eur J Pharmacol 2008;585:441-52.

71. Melchior M, Bolze C, Fombonne E, et al. Early cannabis initiation and educational attainment: is the association causal? Data from the French TEMPO study. Int J Epidemiol 2017;46:1641-50.

72. Newton NC, Teesson M, Vogl LE, et al. Internet-based prevention for alcohol and cannabis use: final results of the Climate Schools course. Addiction 2010;105:749-59.

73. Ariza C, Pérez A, Sánchez-Martínez F, et al. Evaluation of the effectiveness of a school-based cannabis prevention program. Drug Alcohol Depend 2013;132:257-64. 